pliances of the ward and sick-room which find a place on the shelve` of the Parkes Museum.

\section{GAS AND ETHER APPARATUS.}

Messrs. MAYER \& Meltzer have constructed for Mr. P. Rhys Griffiths, of the Cardiff Infirmary, a small apparatus by which the administration of gas and ether is greatly facilitated. This consists of three tubes (A B C) meeting together in a cylindrical horizontal chamber (D), in which a valve (E), shown in section, revolves. The tube $A$ is attached to the tube which fits the mouth-piece of a Clover':

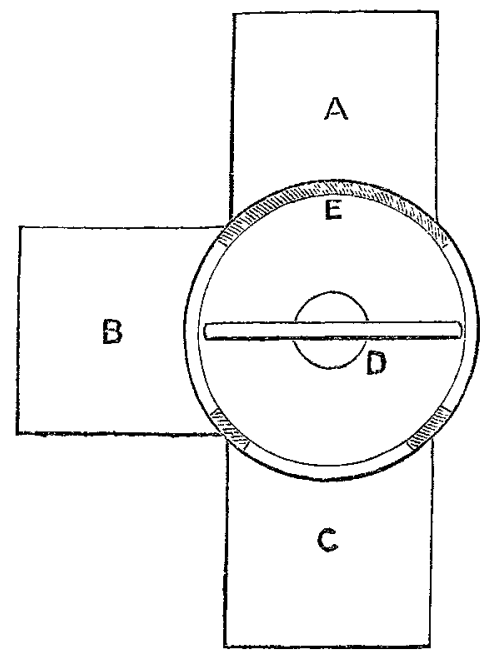

ether inhaler; the mouth-piece of the inhaler is fixed to the tube $\mathrm{c}$, and the tube $\mathrm{B}$ is fixed to the pipe leading from the reservoir of gas. In the administration of gas and ether, the valve, by means of a handle outside the chamber (D), is made to revolve so that the opening in the tube fixed to the ether apparatus is occluded; the gas is then allowed to pass through the tube $B$ and be inhaled by the patient. As soon as the patient has been brought sufficiently under the in fluence of the gas, the motion of the valve is reversed, the tube $\mathrm{B}$ shut, and the tube A opened; the ether vapour is then allowed to pass gradually through the horizontal chamber to be inhaled by the patient.

\section{ST. ANDREWS GRADUATES' ASSOCIATION.}

THE fifteenth anniversary session of the Association was held at the house of the Medical Society of London on June 30th. The treasurer's report showed a flourishing state of the funds. The report of the Council congratulated the members on the avowed intention of the Government to withdraw the clause in the Universities (Scotland) Bill, by which power was given to the commissioners to dissolve the University of St. Andrews; also on their purpose to retain a representative of St. Andrews on the Medical Board for Scotland. Stress was laid on the need of close union so that every effort might be made to retain and to extend the medical faculty of the university; and promise was given of an early meeting to consider the best means of aiding the university and the chairs of the medical faculty by a money contribution from the graduates and their friends.

The anniversary dinner was held in a very beautiful and pleasant room of the Holborn Restaurant, where an excellent meal was served. Dr. Richardson, F.R.S., was in the chair. Among the visitors were Lord Balfour of Burleigh, Sir Joseph Fayrer, K. C.S. I., Dr. Hassall, and Dr. Hayward; and among the numerous graduates present were Drs. Seaton (of Sunbury), Cholmeley, Cleveland, Cooper Rose, Royston, J. Sedowick (of Bordbridge). Watkins, Murray Lindsey (of Mickleover), Semple, Paul, Hicks (of Hendon), Stamper (of Pembroke Dock), Curgenven (of Derby), Longhurst, and Leonard Sedgwick

The following officers were elected for the ensuing year :President of Council : Dr, Richardson, F,R,S, Treasurer :
Dr. Paul. Secretary: Dr. Leonard Sedgwick. Council Drs. Archibald, Alderson, Bynes, Cholmeley, Christie, Cleveland, Corner, Crosby, Dale, A. G. Davey, J. G. Davey, Davies, Gillespie, Gordon, C.B., Griffiths, Henty, Hicks, Hill, Hood, Kesteven, Murray Lindsay, Lipscombe, Longhurst, McMenzies, Professor Pettigrew, F.R.S., D1s. Pocock, Royston, Seaton, J. Sedgwick, Semple, Smitb, Stamper, Tibbitts, Wilkinson, Willett, Rhys Williams, and Wyman.

\section{"IS PNEUMONIA INFECTIOUS?" To the Editor of THE LANCET.}

SIR, - There have been several annotations published lately in your columns on the subject of infectious pneumonia, and in the last number of your valuable journal there appeared one giving particulars of two outbreaks of epidemic pneu. monia which occurred on the Continent. That such epidemics of this disease take place occasionally gives (as is very truly remarked in the article to which I am alluding), much support to the belief which is now held by many observers in the truly specific nature of pneumonia. Patting aside, however, these well-marked epidemics, a great many medical men must have noticed the suggestive fact that cases of this disease scarcely ever come singly, and sometimes, as I myself have more than once observed, a group of cases may occur in only one geographical direction. During last year I witnessed two instances of what appeared to be communication of ordinary croupous pneumonia by con. tagion. I will relate them briefly.

In the first case, Ada $\mathrm{C}-$, aged seven, living in a small village, was attacked with preumonia on April 9th, 1882. The base of the right lung only was affected, the fever did not run very high, and a crisis occurred on April 15th, and was followed by recovery. During her illness she was nursed almost entirely by her father, who was a fairly strong man, fifty-seven years of age, and accustomed to an out-door life. On April 17th he had a rigor, followed by the ordinary symptoms of inflammation of the lung, and he died after an illness of only seven days, on April 24th. The lung mischief was in his case also confined to the right base, and although the temperature never exceeded at any observation $103^{\circ}$, and though he was able to take nourishment and stimulants freely, he showed signs of great prostration from the first, the immediate cause of death being eventually heart failure. I may mention here that there was no evidence of any sanitary defects in the surroundings.

The second case is as follows. Mary W-, aged thirteen, daughter of a farm labourer, came under my care on August 21st, suffering from pneumonia, right base and middle lobe being inflamed. She had a severe attack, but a crisis came on the sixth day (Angust 26th), and she made a good recovery. On the 3rd of September her little sister Martha, aged three, was seized with inflammation of the left lung. The disease ran a very short course, convalescence being established by crisis on the fourth day. These two cases occurred in a country cottage, well situated, and free from any discoverable insanitary condition.

Of course, in the cases I have related mere coincidence might account for what otherwise is very strongly suggestive of an extension of the disease by infection. I do not, therefore, wish to dogmatically assert that they were examples of contagious pneumonia, though I must express my own firm belief that they were. I hope my publication of these cases may induce other country practitioners to bring forward evidence that may throw light upon this very interesting and important point.

I am, Sir, your obedient servant, ALbert E. May, L.R.C.P. Lond., \&c. Moretonhampstead, S. Devon, June 23rd, 1883.

Sanitary Institute of Great Britain.-At the anniversary meetivg of the Institute, to be held in the theatre of the Royal Institution, Albemarle-street, on Thursday, July $12 \mathrm{hh}$, at 3 P.M., the chair will be taken by Prof. Humphry, M.D., F.R'S., and an address will be delivered by W. Eassie, C.E., F.L.S., F.G.S., entitled "The Relationship between Geology and Sanitation." The medals and certificates awarded to the successful exhibitors at the exhibition at Newcastle in 1882 will be presented at the meeting. 